\title{
Rapid alloy prototyping for strip steel development: DP800 steel case study
}

\author{
Y. Zhu, C. Slater, S. Connolly, D. Farrugia \& C. Davis
}

To cite this article: Y. Zhu, C. Slater, S. Connolly, D. Farrugia \& C. Davis (2021) Rapid alloy prototyping for strip steel development: DP800 steel case study, Ironmaking \& Steelmaking, 48:5, 493-504, DOI: $10.1080 / 03019233.2021 .1880036$

To link to this article: https://doi.org/10.1080/03019233.2021.1880036

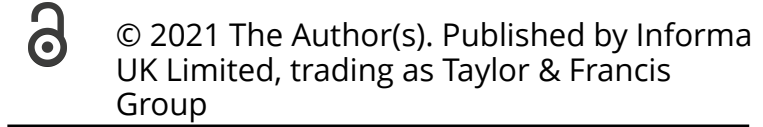
UK Limited, trading as Taylor \& Francis Group

曲 Published online: 21 Feb 2021.

Submit your article to this journal \lceil

Џll Article views: 166

Q View related articles $\sqsubset$

View Crossmark data $\nearrow$ 


\title{
RESEARCH ARTICLE
}

\section{Rapid alloy prototyping for strip steel development: DP800 steel case study}

\author{
Y. Zhu ${ }^{a}$, C. Slater (D) a , S. Connolly ${ }^{a}$, D. Farrugia ${ }^{b}$ and C. Davis ${ }^{a}$ \\ ${ }^{a}$ Warwick Manufacturing Group (WMG), University of Warwick, Coventry, England; ${ }^{b}$ Rolling Finishing \& Measurement Department, Tata Steel \\ Europe, London, UK
}

\begin{abstract}
Alloy development on a commercial scale in recent years has become much more costly and as such has adopted a more iterative approach, making small refinements while keeping within known limits. Laboratory-based rapid alloy development is therefore a key in pushing new grade boundaries. This work shows the rapid alloy development (RAP) facilities at WMG, including capability, sizes and time required for each stage of the process, which have been mapped against the relevant industrial process. A case study of a dual-phase steel grade DP800 has been used for this work. It has been shown that through knowledge of the strengthening mechanism of the alloy (2nd phase distribution for DP800) is critical with respect to mechanical properties and that specific changes and optimisation to the laboratory production casting and subsequent reduction allows for the final product microstructure and mechanical properties to match the production product. This gives confidence in upscalability.
\end{abstract}

ARTICLE HISTORY

Received 28 October 2020 Revised 11 January 2021

Accepted 15 January 2021

\section{KEYWORDS}

Dual-phase steel; rapid alloy processing; product benchmarking; process modelling; 2nd phase band spacing; thermomechanical processing; Ferrite grain size; Strength and elongation optimisation

\section{Introduction}

New grade/process parameter development for mass-produced steel strip via large scale $2 \times 30 \mathrm{~kg}$ pilot plant and mill trials is a time- and cost-intensive process. This has imposed up to now restrictions in view of turn-around lead time and operator/equipment capacity. A lot of the current developments to a more iterative approach and limited to selected changes in composition and/or process parameters with a risk-averse approach. Many laboratories that developed steels have focussed on novel high-alloy steels where composition and/or heat treatment dominate properties as commercial cast microstructures and thermomechanical processing is difficult to replicate. There is, therefore, a need to develop a high throughput processing and testing route, representative and benchmarked to commercial strip steel production, for simulation of new chemistries, and evaluation of associated downstream processing requirements to reduce the time between an alloy design idea and the final evaluation of mechanical and microstructural properties from months to days [1].

Rapid alloy prototyping (RAP) allows for fast investigation of systematic variations or completely new alloy systems through the combination of small-scale processing and mechanical testing and simulation-based modelling. Enabling testing within research laboratories and virtual environments rather than in the steel plant means hundreds of samples can be produced and tested in the time it currently takes to test one new steel composition via pilot plant and mill trials and a lot less material is wasted [2].

RAP has been widely applied as an experimental approach to develop bulk structural materials through compositional and thermo-mechanical design processing and validation based on scaled-down samples. For example, Springer [3] established a lab-based through-process replication methodology to investigate the influence of alloying elements (e.g. Al) on the strengthening mechanism in 30-Mn-1.2C-xAl triplex steels during aging. Five alloy compositions, nine different aging treatments as well as 45 samples for microstructure characterisation and mechanical tests can be made from a single master $20 \mathrm{~kg}$ cast trial, utilising a specially designed VIM cast mould. QuesTek [4] established a proven systems-based Integrated Computational Materials Engineering (ICME) approach and a 'Materials by Design' methodology to design and deploy new metallic materials (e.g. ultra-high strength and stress corrosion-resistant steel grades, fracture toughness enhanced forged alloy steel grades) in a fraction of time and at much lower cost than traditional empirical trial and error approach. The key factor for their success is the ability to predict the effect of composition and heat treatment histories on microstructure using computational modelling tools and validate by additive manufacturing processes. Therefore, the link between that microstructure to key properties can be determined within a shorter period than the conventional research and development cycle.

The previous rapid alloy developments mentioned above focused around small batch and producing one off components. These materials obtain the majority of their properties from the chemical composition rather than process (thermal plus mechanical) history and therefore don't need to consider the implications of lab-based trials scaling up to full production. Work by the University of Swansea has shown that taking this rapid production approach to steel alloy development can yield extremely fast results and show clear trends in properties that would be expected [5]. This rapid alloy assessment approach (both computationally and experimentally) can be seen in the development of creep-resistant steels [6] and microalloyed steels [7]. Again, current alloy 
Table 1. Process route and number of samples available at each stage.

\begin{tabular}{|c|c|c|c|c|}
\hline $\begin{array}{l}\text { Lab simulation } \\
\text { routes }\end{array}$ & Lab facilities chosen for the benchmark alloy & $\begin{array}{l}\text { Typical lab material size } \\
(\mathrm{mm})\end{array}$ & Quantity & $\begin{array}{l}\text { Time to } \\
\text { process }\end{array}$ \\
\hline Casting & Vacuum Induction Melting Furnace (VIM) & $220 \times 800 \times 30$ & 1 & $\leqq 3 \mathrm{~h}$ \\
\hline Reheating slab & Muffle furnace & $35 \times 80 \times 30$ & 6 & હ1 h \\
\hline Hot rolling & Muffle furnace + Hille mill (or Gleeble simulation) & $300 \times 80 \times 3$ & 6 & $\lesseqgtr 30 \mathrm{~min}$ \\
\hline Coil cooling & Air cooling + Fluidised bed furnace & & & $\leqq 12 \mathrm{~h}$ \\
\hline Descaling & Sand blaster & & & $\lesseqgtr 30 \mathrm{~min}$ \\
\hline Cold rolling & Hille mill & $300 \times 80 \times 1$ & 12 & $\leqq 30 \min$ \\
\hline Annealing & Muffle furnace + fluidised bed furnace (or Gleeble/ETMT) & $150 \times 80 \times 1$ & 24 & $\lesseqgtr 30 \mathrm{~min}$ \\
\hline Mechanical testing & $\begin{array}{l}\text { Instron tensile machine or Electrothermal Mechanical Testing } \\
\text { machine (ETMT) }\end{array}$ & ASTM E8 & $\begin{array}{l}10 \text { per annealed } \\
\text { strip }\end{array}$ & $\leqq 5 \min$ \\
\hline
\end{tabular}

assessment has been laboratory-based with little/no comment of scalability.

In contrast, the RAP in this study not only aims to be able to rapidly assess a wide range of compositions but additionally address the scientific challenges associated with commercial processing for strip steels, however, to achieve this appropriate benchmarking is needed to confirm that both the microstructural development and final properties in the laboratory RAP material are representative of the commercial material.

A steel grade that relies on both chemistry as well as processing conditions is the family of dual-phase steels. DP800 is a cold-rolled and annealed dual-phase steel with a high ultimate tensile strength (UTS) of approximately $800 \mathrm{MPa}$ combined with good formability (around 14\% total elongation) that makes it suitable for light deep drawn or crash formed components such as body-in-white structural and reinforcement components and light-weight seat structures [8]. These properties stem predominantly from the phase balance and distribution of the ferrite and martensite [3]. The soft ferrite phase is generally continuous, providing high ductility, and allows a high build-up of strain during deformation, giving high work hardening; the hard martensite phase provides strengthening. Behaving like a composite material, the correct proportion (and distribution) of the two phases allows a continuous yield point, high elongation value and a smooth flow stress curve up to a high ultimate strength, combined with a high strain hardening coefficient, plasticity and formability [9]. For this reason, DP800 was chosen as the case study for the RAP process reported here.

\section{Steel RAP route}

Established in 2017, the RAP process aims to simulate the compositions, microstructures and main processing conditions seen in full-scale production of commercial strip steels.

For casting a selection for induction furnaces allowing ingots of between $200 \mathrm{~g}$ and $8 \mathrm{~kg}$ are available to produce targeted compositions. In addition, steel/slag interactions, liquid contraction during solidification and heat transfer can be considered for alloys where these aspects limit commercial production.

Hot and cold rolling is carried out in a Hille mill (using a two high or four high configurations), rolling up to 80 $\mathrm{mm}$ wide strips. The $80-\mathrm{mm}$ width allows whole expansion test samples, as well as both longitudinal and transverse ASTM E8 sub-sized tensile specimens to be assessed. Controlled cooling simulating coiling post hot rolling is carried out using a fluidised bed where large samples (typically around five strips of $500 \times 80 \times 3 \mathrm{~mm}$ ) can be accommodated. Hot rolling with laboratory equipment (within a maximum speed of $0.2 \mathrm{~m} \mathrm{~s}^{-1}$ ) results in higher temperature losses (around $50^{\circ} \mathrm{C}$ in conduction to the rolls and radiative to the atmosphere) than are seen during commercial rolling (albeit at larger rolling speed), therefore, intermediate heating between rolling passes in a furnace is required to maintain sample temperature, for example above the no-recrystallisation temperature (TNR). If a greater control during rolling is needed, for specific strip grades, then the Gleeble HDS-V40 is used which provides precise thermomechanical control for the assessment of precipitation, recrystallisation and grain growth kinetics during processing.

The hot-rolled strip samples are cold rolled to the required final product thickness then annealing can be performed using a combination of muffle furnaces and fluidised beds. For the rapid assessment of the impact of commercial heat treatments, such as continuous annealing processing line parameters where annealing temperatures, times and rate vary then the Gleeble HDS-V40/Gleeble 3800 or Phoenix electro-thermo-mechanicaltester (ETMT) can be used with the latter two having direct tensile testing capability of the heat-treated samples.

The production route to final product typically takes around 4-5 days including EDM machining (to minimise geometries tolerance and residual stress) and mechanical testing (tensile, Charpy, hole expansion testing). From one cast ingot a number of processing variables can be assessed (number of samples and hence process parameter trials for each stage are summarised in Table 1). Once the route is established for a specific strip steel grade and process then scientific questions and assessment of the impact of variations of chemistry/processing variables can be carried out to optimise current products or develop new grades. The work presented below is a case study on the detailed development of the RAP process variables based on sound scientific principles for DP steels to allow confidence in the upscalability of laboratory findings for mass-produced steel products.

\section{Materials and methodology}

\section{Commercial DP800}

For benchmarking of the RAP route, a commercially produced DP800 was used with a final product thickness of $1.2 \mathrm{~mm}$. Historic plant data has been made available for this product with over 5000 coil analyses providing the full distribution of commercially achieved compositions and properties; for confidentiality purposes, these values have been normalised. The critical microstructure features in the final product are summarised in Table 2 . These values will be compared with the laboratory benchmark alloy to 
Table 2. Measured key microstructure features of the DP800 commercial $1.2 \mathrm{~mm}$ product.

\begin{tabular}{|c|c|c|c|c|c|c|}
\hline$\%$ of ferrite & $\begin{array}{c}\% \text { of } \\
\text { martensite }\end{array}$ & $\begin{array}{c}\% \text { of tempered } \\
\text { martensite + bainite }\end{array}$ & $\begin{array}{c}\text { Band } \\
\text { spacing }(\mu \mathrm{m})\end{array}$ & $\begin{array}{c}\text { Ferrite grain size } \\
\mathrm{RD}(\mu \mathrm{m})\end{array}$ & $\begin{array}{c}\text { Ferrite grain size } \\
\text { ND }(\mu \mathrm{m})\end{array}$ & $\begin{array}{c}\text { Ferrite aspect } \\
\text { ratio }\end{array}$ \\
\hline $69.2 \pm 2.0$ & $25.9 \pm 2.4$ & $4.9 \pm 1.1$ & $4.4 \pm 1.3$ & $4.2 \pm 1.8$ & $2.9 \pm 1.2$ & 1.45 \\
\hline
\end{tabular}

evaluate whether the lab benchmark trial has successfully replicated industrial material.

Typical microstructures of this product can be seen in Figures 1 and 2 . The contrast between martensite bands and ferrite grains is clearly seen in the optical micrograph, Figure 3. Some bainite or tempered martensite can be seen from the SEM image (SE detector used) on a lighter etched surface, as shown in Figure 2, where the total fraction of second phase is $30.8 \%$. This is typical for a DP800 where second phase fractions have been seen to vary between $20 \%$ and $40 \%$ [10]. The microstructures show the characteristic banded structure due to segregation during casting and heavy rolling reduction. The banded second phase affects the ferrite grain size with restriction of ferrite growth in the normal direction on recrystallisation/grain growth during continuous annealing as seen by the $>1$ aspect ratio of the ferrite grains.

\section{RAP process: casting}

Table 2 shows the band spacing in the final commercial product is around $4.5 \mu \mathrm{m}$. For a commercial product, this will have come from the segregation in a 230-mm thick cast slab that has then had around $x 192$ rolling reduction (for a 1.2-mm final product). With the limitation of cast/rolling thickness on the lab scale, then the amount of reduction achievable is reduced. Therefore, rather than trying to replicate the commercial cast product, the lab cast needs to achieve microstructural characteristics (dendrite spacing and segregation in this case) that will result in the final laboratory product having similar properties to the commercial final product. This can be achieved through mould design considering the cooling rate required to achieve a segregation spacing that, with the laboratory rolling reduction, gives the required final product band spacing. It is well understood that increasing cooling rate reduces the secondary dendrite arm spacing (SDAS) of solidifying material and therefore the segregation pattern [11]. A cooling rate/rolling reduction combination can be chosen that results in a final band spacing of around $4.5 \mu \mathrm{m}$. A COMSOL 5.5 Multiphysics was used to determine the cooling rate for different ingot sizes. The setup to model solidification in the mould can be seen in Figure 3, where the mould width is set to $80 \mathrm{~mm}$ due to rolling limitations downstream, however, the thickness is variable affecting the cast cooling rate and therefore the SDAS.

The cooling profile for a range of mould thickness from 10 to $50 \mathrm{~mm}$ is seen in Figure 4(a), with the cooling rate during solidification being shown in Figure 4(b) (using the liquidus and solidus temperatures defined by Thermo-Calc TCFe10).

The relationship between SDAS and cooling rate is known for many alloys. For DP800, both literature [11] and internal testing has shown this to be:

$$
\mathrm{SDAS}=84 \mathrm{CR}^{-0.45} \text {. }
$$

Using this relationship then the SDAS for the different cooling rates/times can be determined, Figure 7(a) and the final band spacing, with is a function of the SDAS, the initial cast size and the desired final strip thickness, $0.8 \mathrm{~mm}$ in this instance can be estimated (Figure 5(b)):

$$
\begin{aligned}
& \text { Final band spacing } \\
& =(\text { Final product thickness }) / \\
& \quad(\text { Cast thickness }) \times \text { SDAS. }
\end{aligned}
$$

It can be seen that in order to achieve a final band spacing in the region of $4.5-5 \mu \mathrm{m}$ in a $0.8-\mathrm{mm}$ rolled strip then a $30-\mathrm{mm}$ thickness mould should be used. This mould was machined from a mild steel block with a $5-\mathrm{mm}$ radius in the corners to allow for easy removal of the cast.

A Consarc $10 \mathrm{~kg}$ VIM was used to produce $4.5 \mathrm{~kg}$ of DP800 made from ferroalloys (listed in Table 3 ). A vacuum of approximately $\times 10^{-5}$ mbar was achieved before back filling with N6 argon to a pressure of $0.2 \mathrm{mbar}$. Initially, just the pure iron, $\mathrm{Cr}$, and $\mathrm{Fe}-\mathrm{Si}$ were placed in the melt crucible. Once fully

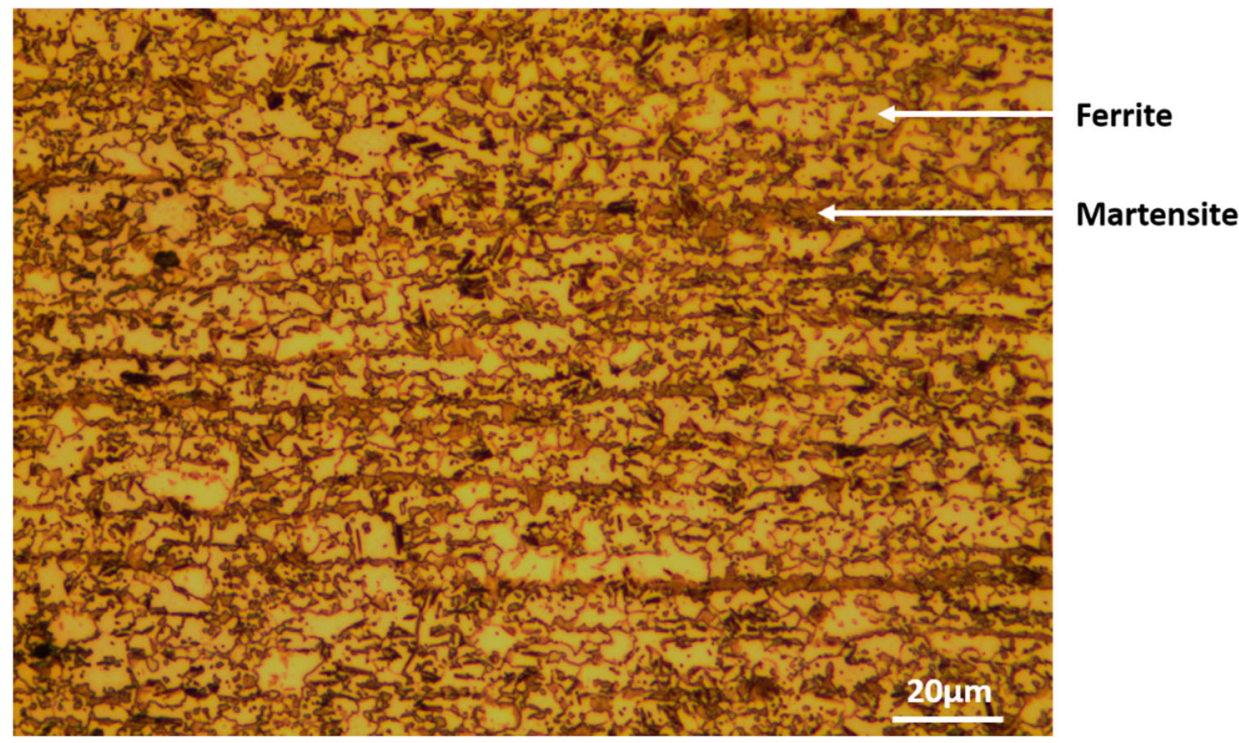

Figure 1. Optical micrograph of commercial DP800 steel showing ferrite grains and martensite bands. 


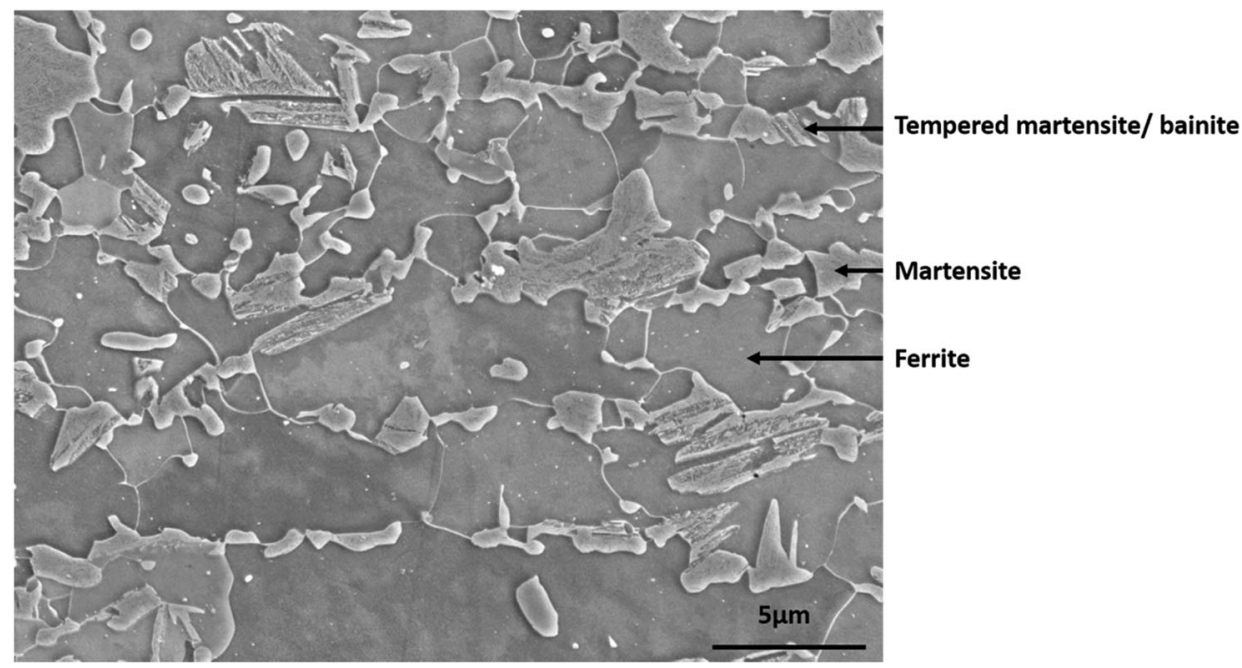

Figure 2. Secondary electron micrograph of commercial DP800 steel, the tempered martensite/bainite phase are differentiated from the martensite grains by the presence of internal contrast.

molten the other additions were made at $1550^{\circ} \mathrm{C}$ where a B-type dip thermocouple was used to ensure a superheat of $30^{\circ} \mathrm{C}$ was applied before pouring into the bespoke $30 \times 80 \times 240 \mathrm{~mm}$ mould.

The cast ingot was cooled down in the mould and then sectioned into 35$\mathrm{mm}$ long transfer bars (width and thickness remain the same) and reheated in a muffle furnace before hot rolling at $\approx 1200^{\circ} \mathrm{C}$ for $1 \mathrm{~h}$ for homogenisation. The rolled sample required reheating between passes with the reheat furnace being set at $900-1000^{\circ} \mathrm{C}$ allowing the transfer bars to be reheated in around $60-120 \mathrm{~s}$. The reheat temperature is above TNR for the DP800 grade (the commercial rolling schedule for the DP800 steel is above the TNR but is low enough to minimise grain growth.

The reheated DP800 transfer bar was hot rolled from 30 to $3 \mathrm{~mm}$ in 10 passes which mimic the commercial rolling from a transfer bar to a finished HR gauge, however in the lab setup an initial 'optimised' cast structure. Rolling was performed in a single direction with the strip being passed from the roll exit back to the roll entrance between each pass to simulate the continuous commercial process, just in case that strain path effect on recovery/ recrystallisation is not developed. Typical geometries produced after the Hille hot rolling are multiple sheets (typically six) of $300 \times 80 \times 3 \mathrm{~mm}$ and this takes around $1.5 \mathrm{~h}$ to process.

Air cooling of the hot-rolled sheet from the finishing mill exit temperature to the coiling starting temperature $\left(600^{\circ} \mathrm{C}\right)$ is monitored via a hand held pyrometer. An alumina Techne FB-08 fluidised bed furnace set at $600^{\circ} \mathrm{C}$ ensures slow cooling of the sheet to the room temperature in $12 \mathrm{~h}$, simulating commercial coil cooling.

The hot-rolled and coil cooled material (e.g. $3 \mathrm{~mm}$ sheet) is then descaled using a sandblaster. The surface conditions are inspected by optical microscopy to ensure $100 \%$ removal of black oxide. The scale-free strip is then passed through the Hille mill at room temperature for the cold rolling simulation, typically producing around 12 sheets of $300 \times 80 \times 1 \mathrm{~mm}$ and taking less than $1 \mathrm{~h}$ to process. In this study, two cold-rolled sheets were made, the first one was rolled from $30 \mathrm{~mm}$ to 1.2 , and $30 \mathrm{~mm}$ to $0.8 \mathrm{~mm}$ for the second one. The aim was to validate the relationship between the product band spacing and rolling thickness reduction ratio/SDAS segregation spacing (Figure 5). During reheating and recrystallisation of the ferrite, grain growth is impeded by the formation of austenite in the banded regions (previous inter-dendritic region), this therefore means the ferrite grain size is directly dictated by the band spacing and hence amount of rolling reduction for the cast ingot meaning this RAP stage is important to assess.

ThermoCalc was used before the annealing simulation to determine the $A c_{1}, A c_{3}, M_{s}$ and $M_{f}$ based on the DP800 composition. The results are $\mathrm{Ac}_{1} \approx 682^{\circ} \mathrm{C}, \mathrm{Ac}_{3} \approx 804^{\circ} \mathrm{C}, M_{s} \approx 400^{\circ} \mathrm{C}$ and $M_{f} \approx 305^{\circ} \mathrm{C}$. These values are compared to the industrial annealing profile used and to guide the RAP heat treatments. The cold-rolled sheet was

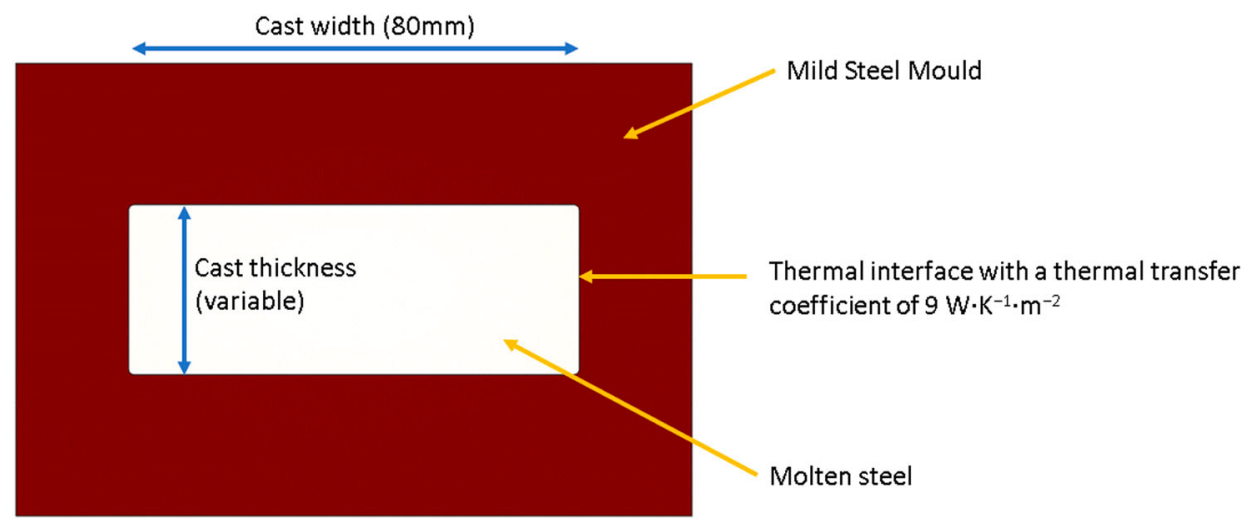

Figure 3. Schematic diagram to show the COMSOL model setup used to simulate the cast ingot cooling rate and hence SDAS. 

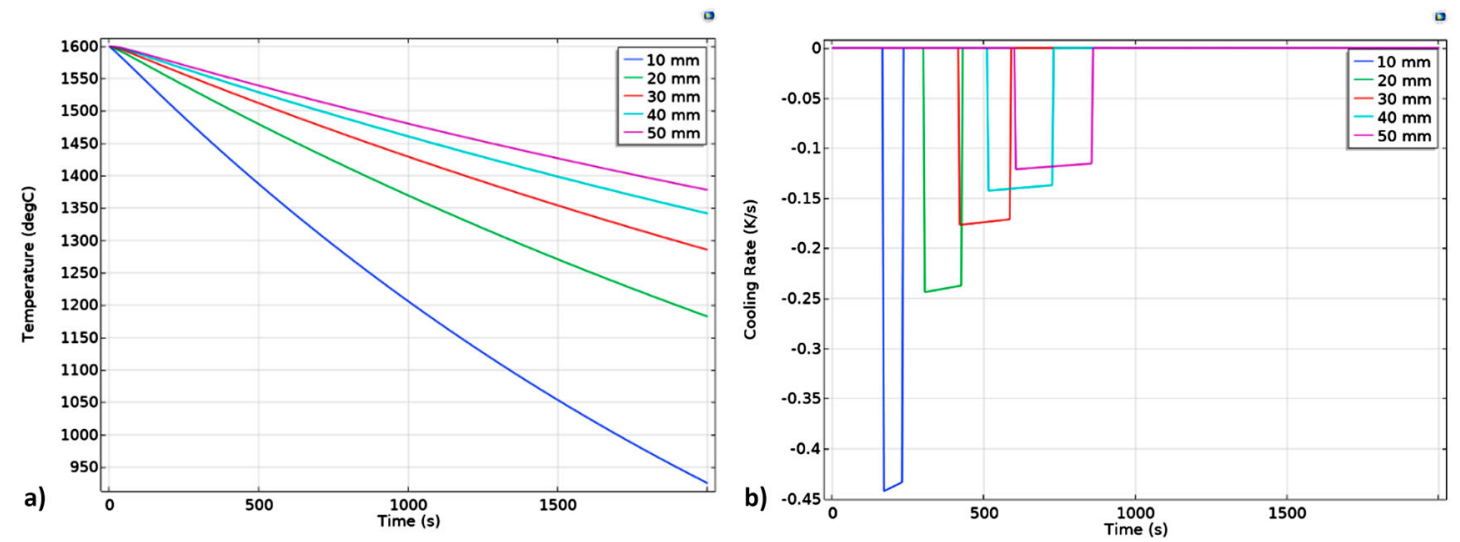

Figure 4. Prediction of the (a) time/temperature curves and (b) cooling rate during solidification for five different mould thicknesses.

sectioned and heated to above Ac3 in a muffle furnace set at $820^{\circ} \mathrm{C}$ (primary reheating temperature) for $2 \mathrm{~min}$. The aim is for the pearlitic carbides to become spheroidised and the deformed ferrite to recrystalise before austenite forms during the holding period. The sheet was then air cooled to the secondary temperature $\left(320^{\circ} \mathrm{C}\right.$, between $M_{s}$ and $M_{f}$ ). Ferrite starts to form and the rapid cooling promotes martensite formation, although some bainite is also desired. The sample was finally put into the fluidised bed set at $320^{\circ} \mathrm{C}$ for $200 \mathrm{~s}$ which autotempers the martensite that forms. No temper pass rolling was applied post autotempering.

In summary, the production and assessment of a single grade can be carried out in $<2$ weeks using the RAP method, with a single $4.5 \mathrm{~kg}$ cast producing enough final product material for the equivalent of 72 tensile specimens, or 20 hole expansion tests allowing a wide range of heat treatments, thermo-mechanical processing variables etc to be investigated in a rapid turn-around time. The route offers opportunities to assess sensitivities to production variations and 'what if' scenarios when developing new alloys/new processing methods.

\section{Characterisation and testing}

Elemental analyses were carried out on the as-cast billet by a combination of an Oxford Instrument Optical Emission Spectrometry (OES) and ELTRA CS2000 Carbon Sulphur (C-S) analyser. For both techniques, a minimum of five measurements were made.

Samples for optical and SEM imaging were sectioned, mounted in conductive Bakelite and ground/polished to a 0.05$\mu \mathrm{m}$ finish using Buehler MasterMet 2 non-crystallised collodial silica solution. $2 \%$ nital was used to etch the polished surface before optical microscope imaging and/or SEM imaging. A JEOL 7800F Scanning Electron Microscope with energy dispersive spectroscopy (EDS) capability was used.

Samples were cut via EDM to subsized tensile specification (ASTM E8M [12]) with $6 \mathrm{~mm}$ gauge width, Figure 6 , and tested following ISO 6892-1:2016 standard with a strain rate of $0.04 \mathrm{~mm}$ $\min ^{-1}$ until yield and $2 \mathrm{~mm} \mathrm{~min}^{-1}$ beyond this. An Instron $30 \mathrm{kN}$ tensile tester was used and the strain measured using an Instron 260-107 clip-on extensometer with a gauge length of $25 \mathrm{~mm}$. The data load, displacement, stress and strain values were collected and analysed by the Instron Bluehill 3 software.

Table 3. Master alloys used for the $4.5 \mathrm{~kg}$ DP800 benchmark cast.

\begin{tabular}{|c|c|c|}
\hline & Composition & Weight (g) \\
\hline Fe Billet & $99.9 w t-\% F e$ & 4342.76 \\
\hline Cr Metal & $99.7 \mathrm{wt}-\% \mathrm{Cr}$ & 24.70 \\
\hline $\mathrm{Fe}-\mathrm{Al}$ & $64 w t-\% F e, 35 w t-\% A l$ & 7.44 \\
\hline $\mathrm{Fe}-\mathrm{Nb}$ & $31 w t-\% F e, 65 w t-\% N b$ & 1.69 \\
\hline $\mathrm{Fe}-\mathrm{Si}$ & $23 w t-\% F e, 75 w t-\% S i$ & 16.05 \\
\hline Carburised Fe-Mn & 7.5wt-\%C, $15.3 w t-\% F e, 77.2 w t-\% M n$ & 82.14 \\
\hline Low C Fe-Mn & $20 \mathrm{wt}-\% \mathrm{Fe}, 80 \mathrm{wt}-\% \mathrm{Mn}$ & 22.25 \\
\hline $\mathrm{Ti}$ & $100 w t-\% \mathrm{Ti}$ & 1.33 \\
\hline Fe-P & 70wt-\%Fe, 27wt-\%P & 1.64 \\
\hline
\end{tabular}
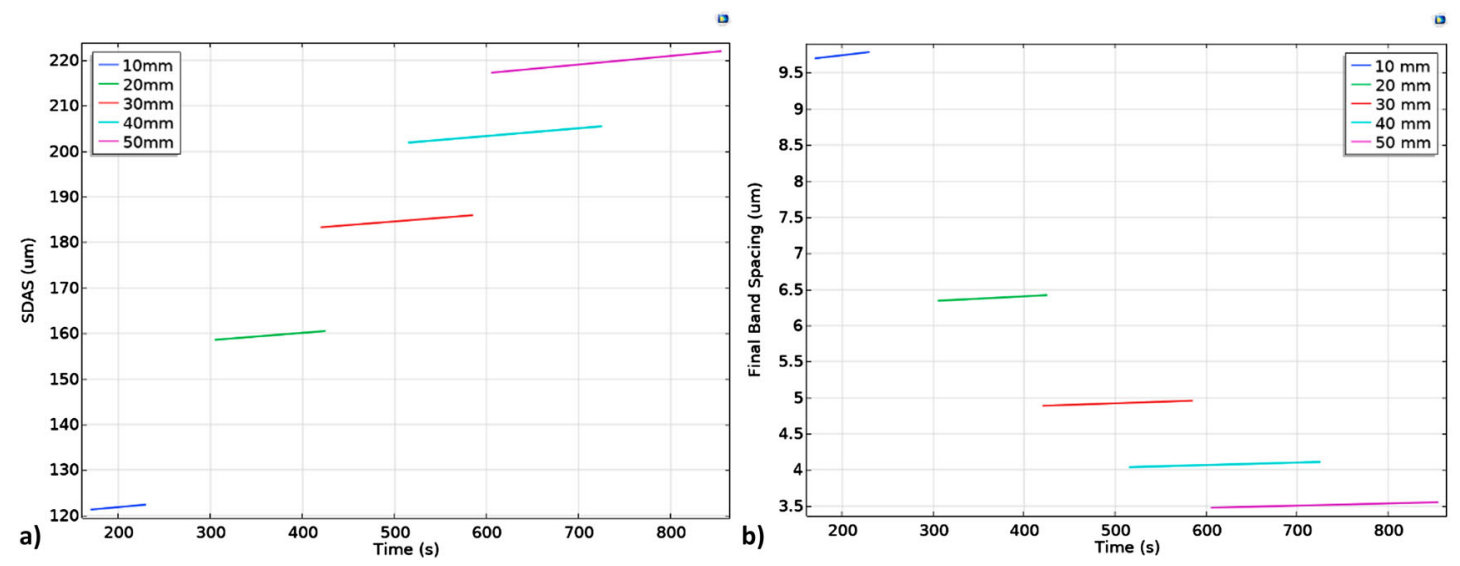

Figure 5. Prediction of (a) the cast SDAS and (b) final band spacing, by using different mould thicknesses in the VIM. 


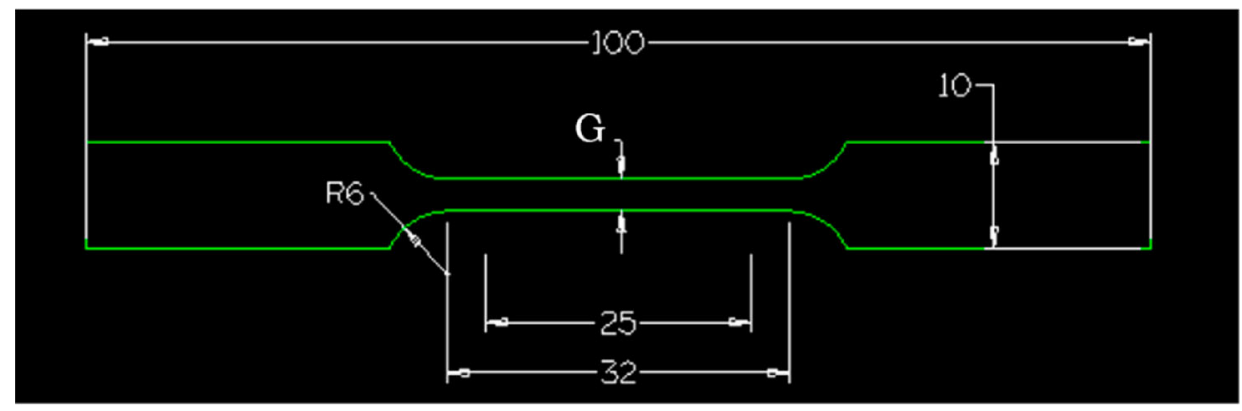

Figure 6. ASTM E8 subsize specimen geometry used for all mechanical testing (adapted from [12]).

\section{Results and discussion}

\section{Compositions}

Table 4 shows the composition of the cast produced in this study. A comparison between the range of industrial product compositions (four main alloying elements) with those of the
Table 4. OES, EDS (for Mn) and C-S analyser results of the lab-produced DP800 benchmark alloy. Values in wt-\%.

\begin{tabular}{lccccccc}
\hline $\mathrm{C}$ & $\mathrm{Si}$ & $\mathrm{Mn}$ & $\mathrm{P}$ & $\mathrm{S}$ & $\mathrm{Cr}$ & $\mathrm{Nb}$ & $\mathrm{Al}$ \\
\hline 0.121 & 0.265 & 1.67 & 0.0091 & 0.003 & 0.535 & 0.023 & 0.0025 \\
\hline
\end{tabular}
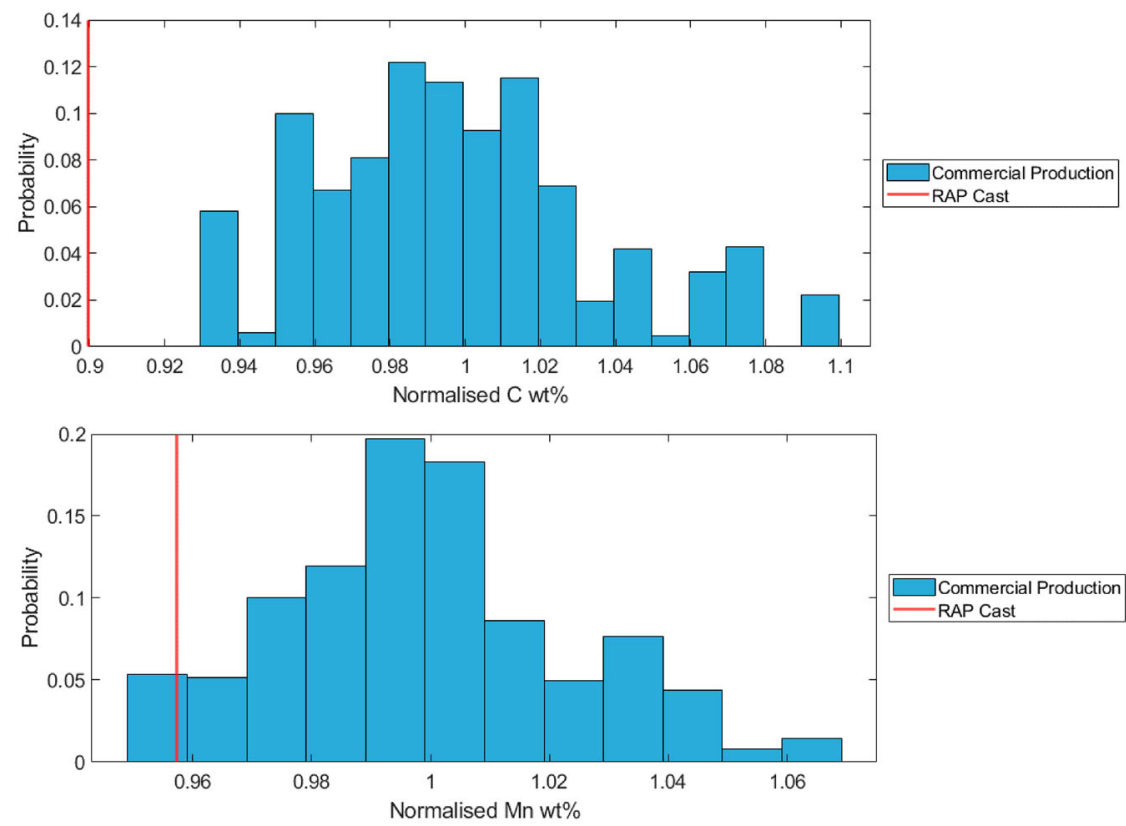

$$
\begin{aligned}
& \square \text { Commercial Production } \\
& \square \text { RAP Cast }
\end{aligned}
$$
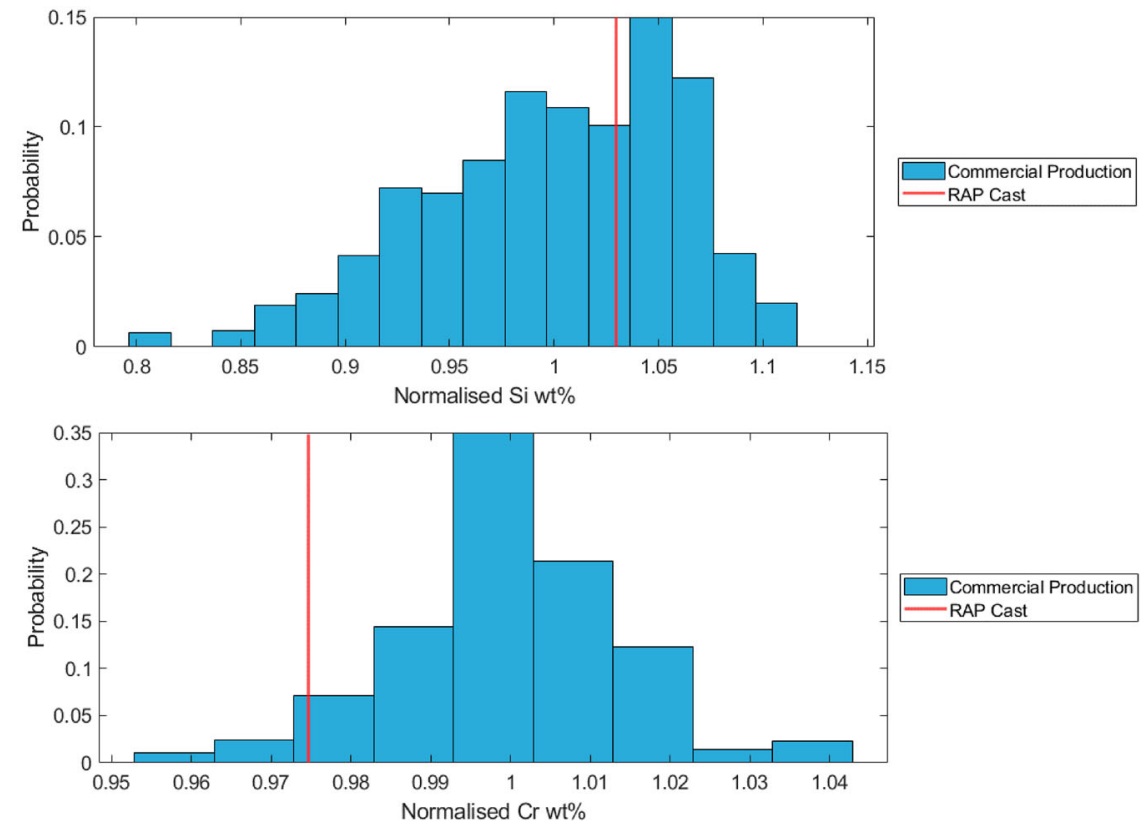

Figure 7. Compositions of the lab DP800 benchmark alloy, compared with the commercial product compositional range. 


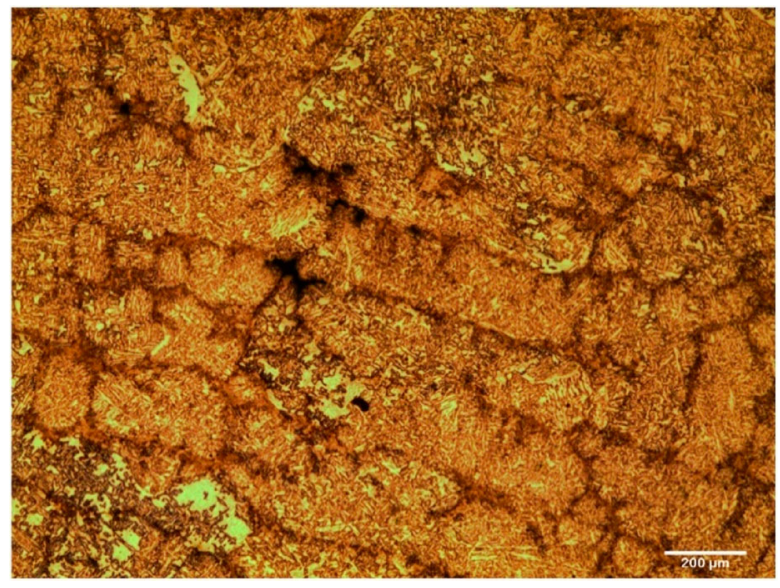

Figure 8. (a) As-cast microstructure showing segregation revealing the dendritic solidification structure.

benchmark cast can be seen in Figure 7. Manganese, silicon, phosphorus, sulphur, niobium and chromium concentrations lie within the range. Both the carbon and aluminium contents are slightly low. This is due to the trace amount of oxygen present in the VIM chamber during casting from a small leak found during a vacuum leak check, which results in oxide formation and loss in carbon and aluminium.

\section{Microstructural analysis}

The as-cast microstructure was analysed and showed evidence of dendritic solidification. Figure 8(a) shows the SDAS formed during solidification with a spacing of $183 \pm 35 \mu \mathrm{m}$ (measured using line intercepts perpendicular to the secondary dendrite arms). This SDAS agrees well with the COMSOL modelling predictions for the mould size and cooling rate (183-187 $\mu \mathrm{m})$.
The microstructures generated after hot rolling and coil cooling simulation is shown by optical microscopy in Figure 9. A typical dual-phase hotrolled microstructure is seen with ferritic grains $(8.7 \pm 4 \mu \mathrm{m}$ with aspect ratio of 2.17) separated by bands of pearlite. This microstructure indicates that the slow cooling in fluidised bed furnace simulating the coil cooling inhibits martensite formation giving a microstructure that compares favourably to the industrial hot band product (shown in Figure 10), although the lab simulated material has a slightly greater band spacing $(8.9 \pm 3.2 \mu \mathrm{m})$ than the industrial material $(8 \pm 2.2 \mu \mathrm{m})$. The commercial hot-rolled material has experienced greater thickness reduction ratio (over 98\%) during hot rolling than the labscale trial $(90 \%)$ when rolled to the same $3 \mathrm{~mm}$ thickness. Therefore, slightly higher cold rolling reduction in the lab route compared to the commercial route is required to match the commercial final product band spacing. Alternatively, modifications to the cast thickness to better match the SDAS/rolling reduction could be used.

The strip is then descaled and samples were cold rolled from 3.0 to $1.2 \mathrm{~mm}$ or to $0.88 \mathrm{~mm}$. The model predictions indicated that the correct band spacing should be achieved by rolling to $0.8 \mathrm{~mm}$; a $1.2-\mathrm{mm}$ thick strip was also produced as a direct comparison to the commercial product thickness.

After following the commercial annealing cycle, SEM micrographs from the RAP and commercial 1.2-mm thick materials are compared in Figure 13 and show very similar microstructures. Detailed data analyses showed a difference in bainite and tempered martensite fraction between these two samples, as summarised in Table 5 . Although the ferrite fraction is the same between the two samples, the amount of tempered martensite plus bainite doubled in the commercial product, although is a low fraction. This might be expected to give greater elongation but lower UTS for the industrial product (Figure 11).

The amount of tempered martensite can be modified during the secondary holding period after air cooling from the primary temperature, which has been shown previously [13]. Several tests were carried out with constant primary heating conditions but varying holding time at $320^{\circ} \mathrm{C}$, the results are summarised in Table 6 and show that an extra $300 \mathrm{~s}$ holding allows more

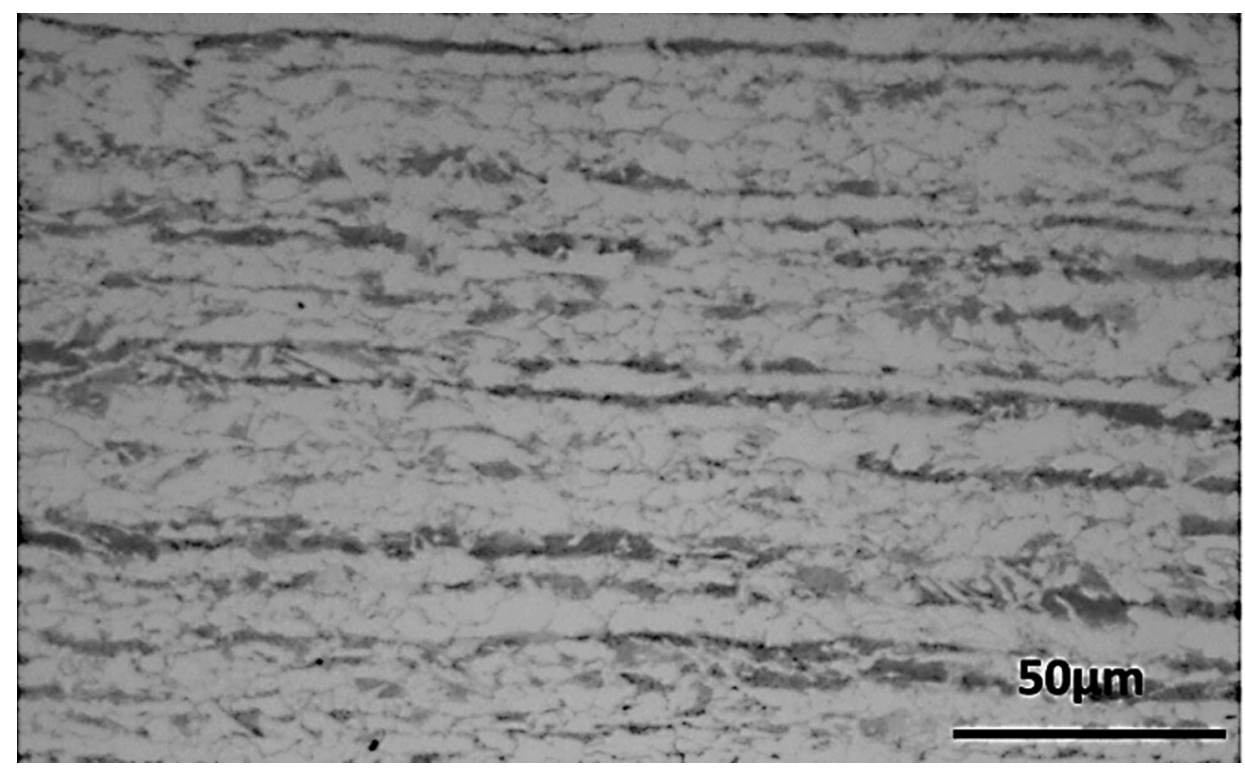

Figure 9. Optical micrograph of the hot-rolled microstructure following coiling simulation in the fluidised bed furnace. 


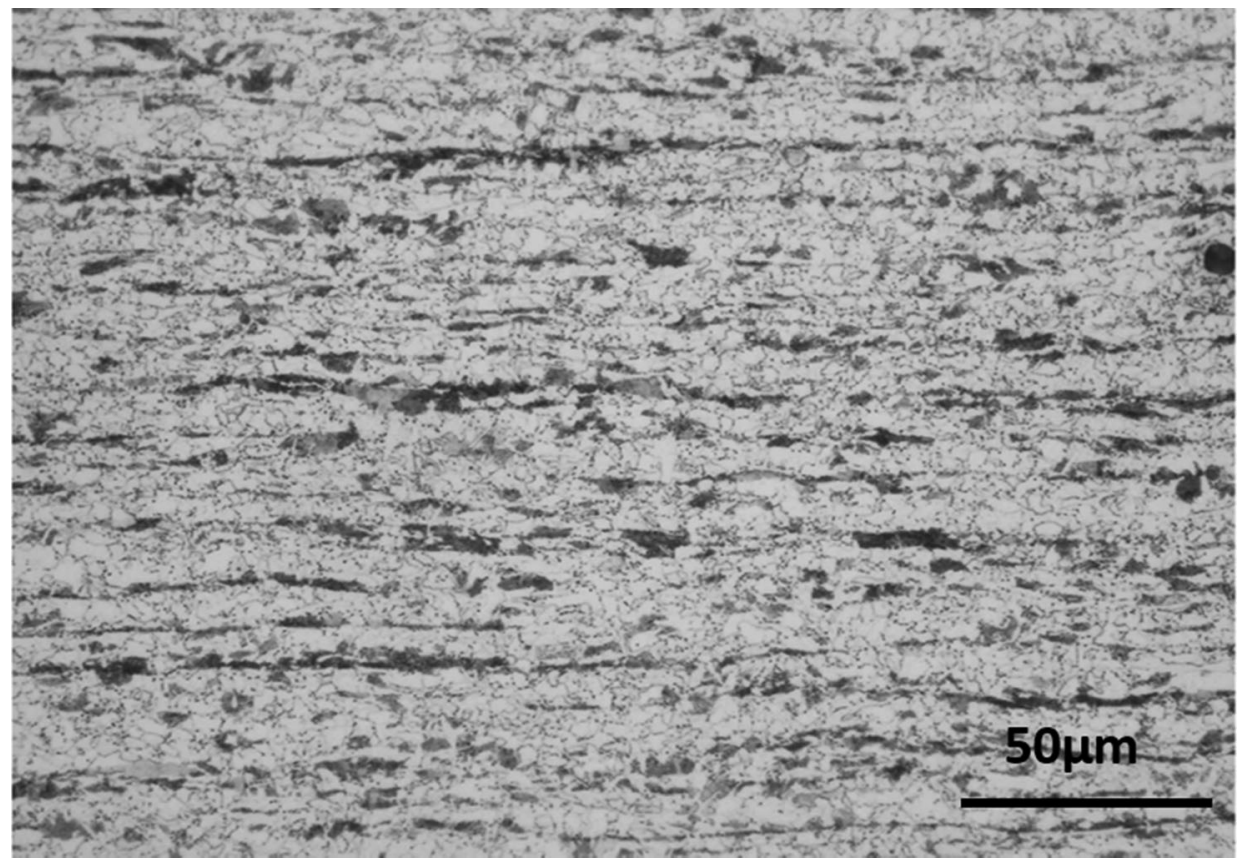

Figure 10. Optical micrograph of industrial hot-rolled product.

time for the tempering process, and effectively bring up the TM phase fraction to $5.4 \%$ (including the pre-formed bainite), which matches more closely the commercial product.

Hardness tests were carried out on the annealed samples (cross-section, rolling direction), the results are summarised together with the ferrite grain size measurements in Table 7. About
$8 \%$ reduction in hardness is found for the lab-produced 1.2-mm thick sample compared to the commercial material; this can be explained by the $34.5 \%$ larger average ferrite grain size than the commercial material of the same thickness.

It is clear that the lab-produced $1.2 \mathrm{~mm}$ sample not only has a greater ferrite grain size but also shows a

Table 5. Fractions of the ferrite, martensite and tempered martensite + bainite within the commercial DP800 and lab benchmark trial.

\begin{tabular}{lccc}
\hline Sample & \% of ferrite & $\begin{array}{c}\% \text { of } \\
\text { martensite }\end{array}$ & $\begin{array}{c}\text { \% of TM }+ \\
\text { bainite }\end{array}$ \\
\hline $\begin{array}{c}\text { DP800 commercial 1.2 } \\
\text { mm }\end{array}$ & $69.2 \pm 2.3$ & $25.9 \pm 2$ & $4.9 \pm 2$ \\
DP800 lab $1.2 \mathrm{~mm}$ & $68.6 \pm 2.5$ & $29 \pm 1.4$ & $2.4 \pm 1.4$ \\
\hline
\end{tabular}

lower amount of $\mathrm{TM}+$ bainite. The second lab sample with a higher amount of cold rolling reduction (from 3 to $0.88 \mathrm{~mm}$ ) and longer secondary holding period at $320^{\circ} \mathrm{C}$ during annealing (from 200 to $500 \mathrm{~s}$ ), had $5.4 \%$ of $\mathrm{TM}+$ Bainite and $3.5 \mu \mathrm{m}$ ferrite grain size) effectively increasing the hardness value to within the standard deviation of the commercial product.

The band spacing of the samples in this study is summarised in Table 8 . The reduced rolling reduction of the 1.2-mm strip can be seen to have a notably higher band spacing as predicted. With a 25:1 reduction, then the initial dendrite spacing from the ingot would result in a predicted $7.2-\mu \mathrm{m}$
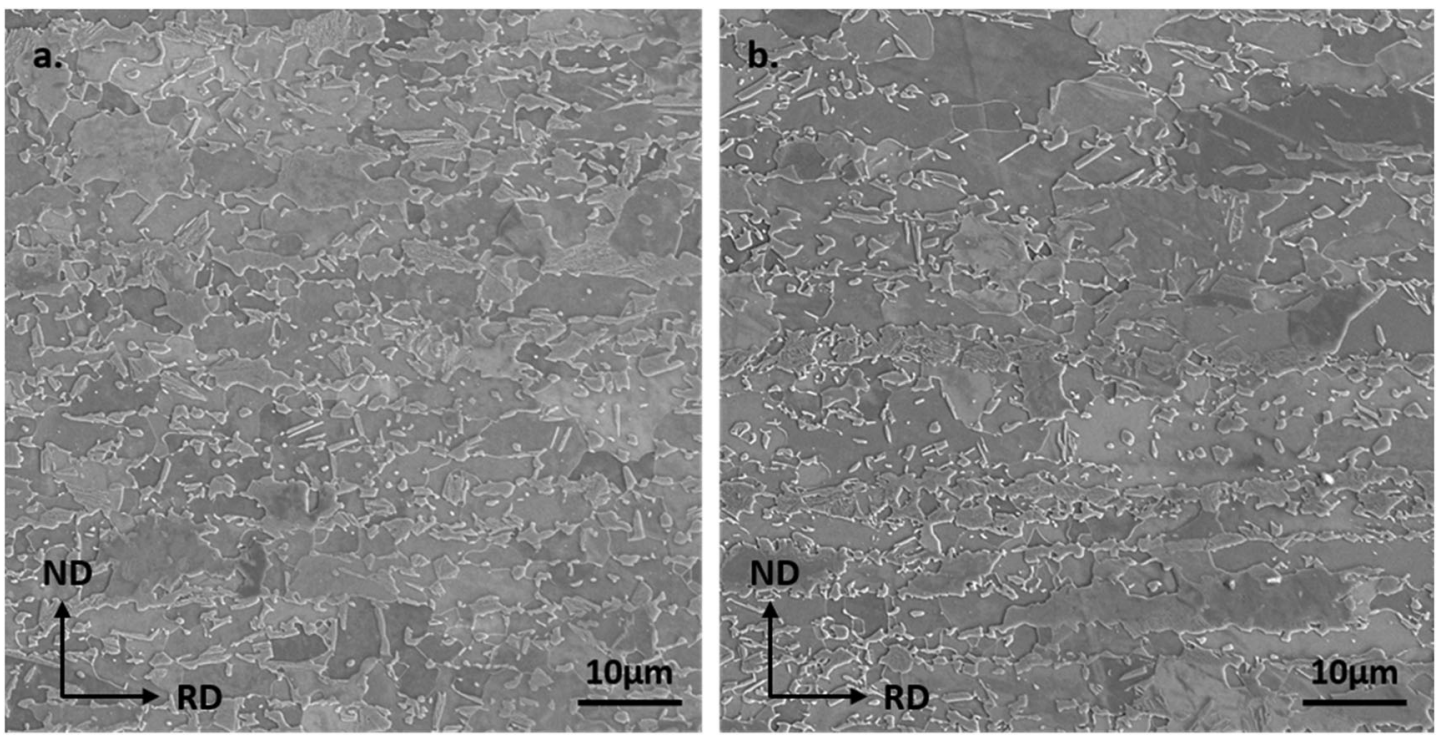

Figure 11. SEM secondary electron images of (a), industrial DP800 product, $1.2 \mathrm{~mm}$ thick; (b), lab simulated DP800, $1.2 \mathrm{~mm}$ thick. 
Table 6. Relationship between the secondary holding time during annealing and the tempered martensite + bainite phase fraction.

\begin{tabular}{lcc}
\hline Sample & Holding time at $320^{\circ} \mathrm{C}(\mathrm{s})$ & $\%$ of TM + Bainite \\
\hline DP800 Lab & 200 & $2.4 \pm 1.4$ \\
& 400 & $4.4 \pm 0.8$ \\
& 500 & $5.4 \pm 1.4$ \\
\hline
\end{tabular}

Table 7. Hardness and ferrite grain size values of the commercial DP800 and lab benchmark materials. The ferrite grain size is measured along the normal direction.

\begin{tabular}{lcc}
\hline Sample & Ferrite grain size $(\mu \mathrm{m})$ & Hardness $\left(H_{V}\right)$ \\
\hline DP800 commercial $1.2 \mathrm{~mm}$ & $2.9 \pm 1.2$ & $246 \pm 6$ \\
DP800 lab $1.2 \mathrm{~mm}$ & $3.9 \pm 1.9$ & $226 \pm 7$ \\
DP800 lab 0.88 mm & $3.5 \pm 1.1$ & $238 \pm 6$ \\
\hline
\end{tabular}

Table 8. Band spacing values of the commercial and lab-produced DP800 samples.

\begin{tabular}{lc}
\hline Sample & Band spacing $(\mu \mathrm{m})$ \\
\hline DP800 commercial $1.2 \mathrm{~mm}$ & $4.4 \pm 1.3$ \\
DP800 lab $1.2 \mathrm{~mm}$ & $6 \pm 2.6$ \\
DP800 lab $0.88 \mathrm{~mm}$ & $5 \pm 1.5$ \\
\hline
\end{tabular}

band spacing (within the error of the measured value). The $0.88-\mathrm{mm}$ strip band spacing is within error of the commercial product but averages slightly above. Based on the initial cast SDAS spacing, the theoretical spacing after rolling to $0.88 \mathrm{~mm}$ is $5.1 \mu \mathrm{m}$, which agrees well with experimental value. A 0.88-mm strip was the thinnest achievable for the lab setup without giving excessive edge cracking. However, a further reduction of $10 \%$ of the $0.88-\mathrm{mm}$ strip to $0.80 \mathrm{~mm}$ should reduce the $5-\mu \mathrm{m}$ band to the target $4.5 \mu \mathrm{m}$.

During the annealing heat treatment, the strip material is heated at a rapid rate during which the ferrite initially

Table 9. Tensile test properties of the commercial DP800 and lab benchmark material.

\begin{tabular}{llcc}
\hline Sample & UTS (MPa) & YS (MPa) & $E_{u(\%)}$ \\
\hline DP800 commercial 1.2 mm & $836.1 \pm 3$ & $492.3 \pm 5$ & $13.3 \pm 0.3$ \\
DP800 lab $1.2 \mathrm{~mm}$ & $777.9 \pm 10$ & $326.9 \pm 5$ & $13.4 \pm 0.7$ \\
DP800 lab 0.88 mm & $810.8 \pm 7$ & $359.8 \pm 9$ & $13.2 \pm 1.3$ \\
\hline
\end{tabular}

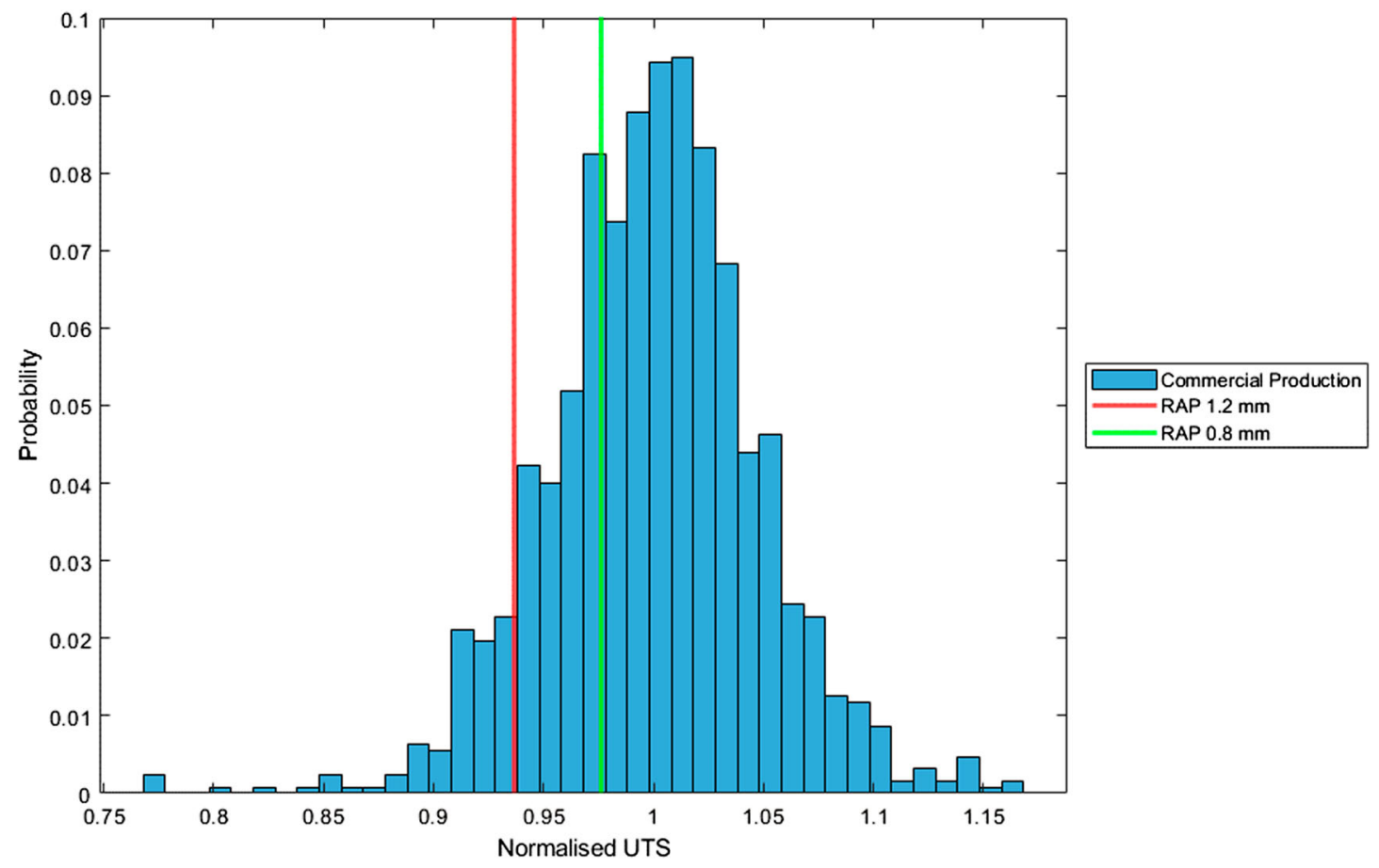

Figure 12. Normalised UTS of the lab DP800 benchmark alloy samples, compared with the commercial product range. 


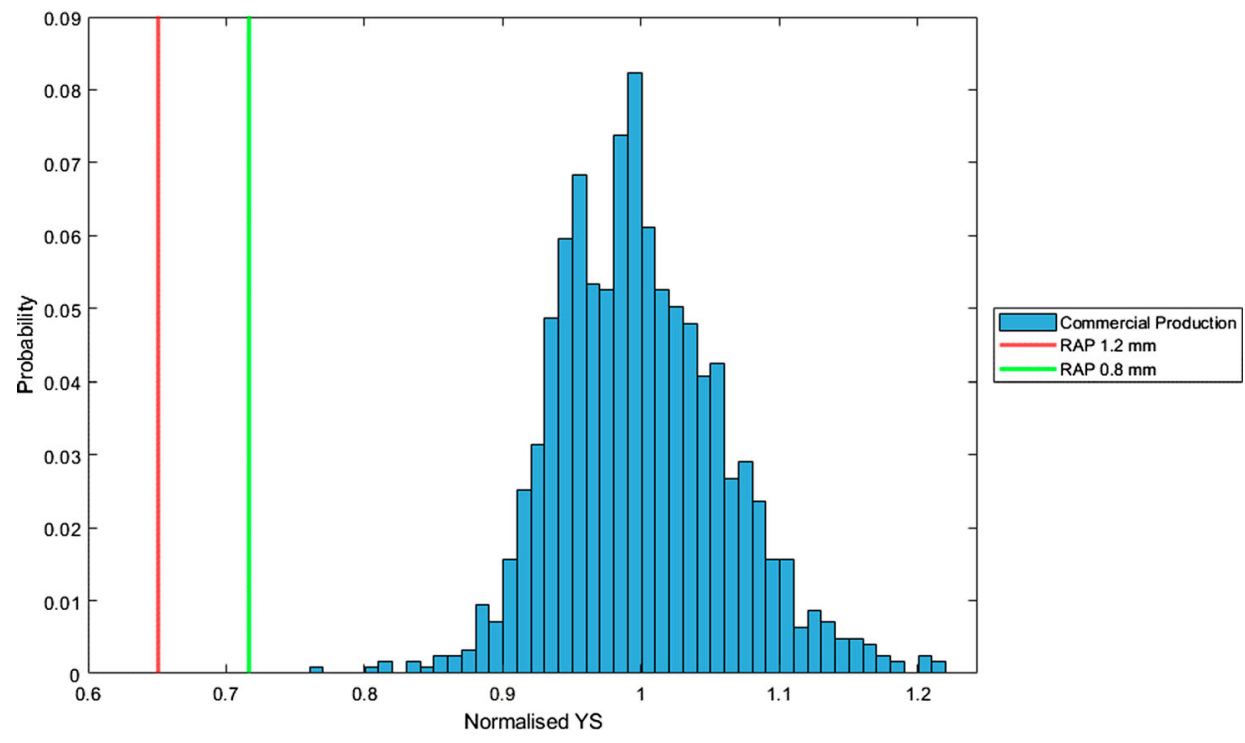

Figure 13. Normalised YS of the lab DP800 benchmark alloy samples, compared with the commercial products range.

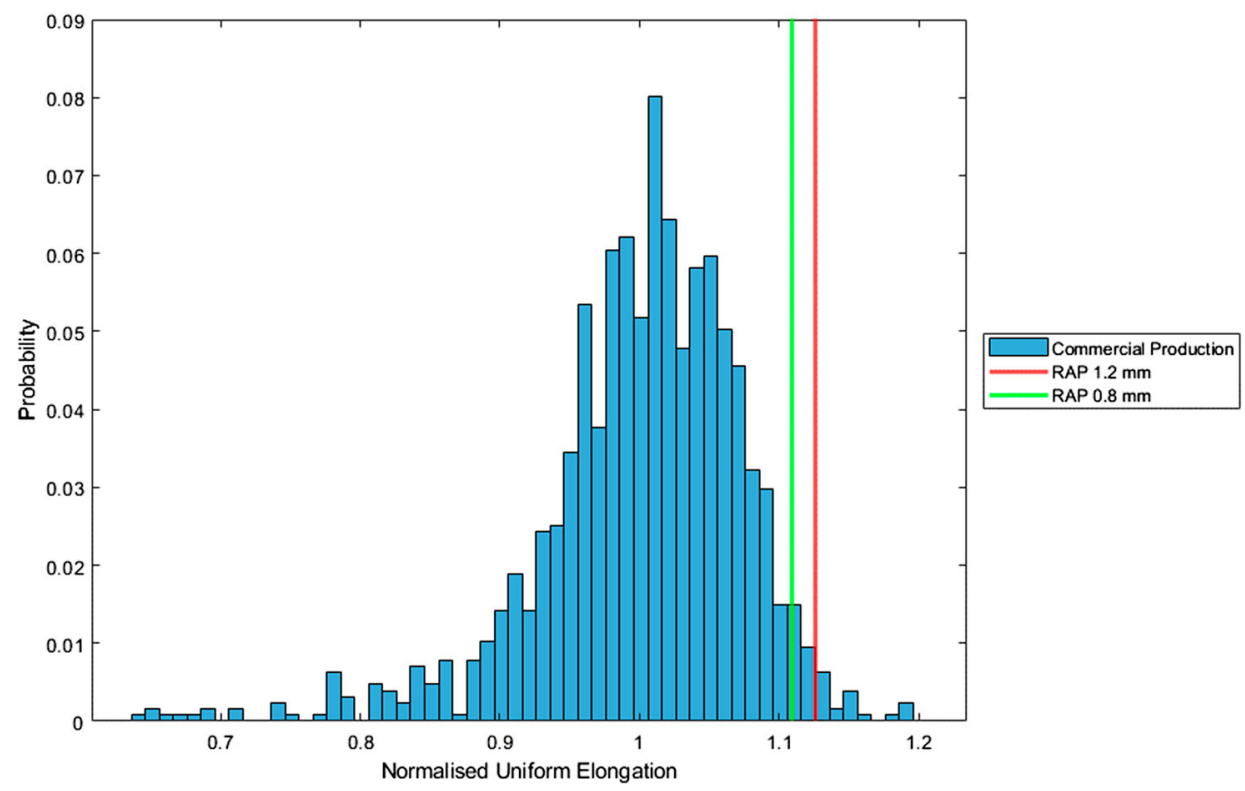

Figure 14. Normalised uniform elongation of the lab DP800 benchmark alloy samples compared with the commercial product range.

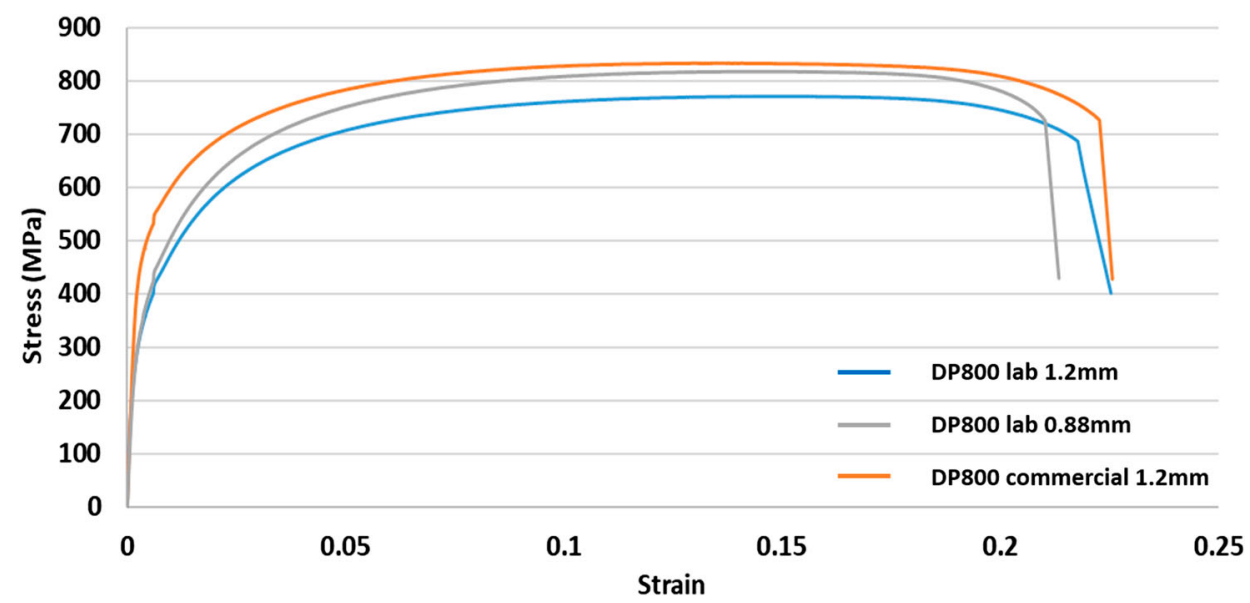

Figure 15. Stress -strain curves of the lab benchmark alloy, with 1.2 and $0.88 \mathrm{~mm}$ thickness, compared to the commercial $1.2 \mathrm{~mm}$ thick material. Samples were cut based on ASTM E8 standard and tested based to ISO 6892-1:2016 standard. 
difference in the YS between the lab material and the industrial material (and range of industrial data) is seen in Figure 13 , this is discussed below. The reduction in sample thickness and the slight difference in $\mathrm{TM}+$ bainite fraction is not expected (or seen to) give any change in uniform elongation. Comparing to the commercial product uniform elongation range (as shown in Figure 14), both the as-received product and the lab benchmark samples have their uniform elongation value above the average but within range.

A comparison between the stress strain curves of the lab and commercial materials is shown in Figure 15. The lab trial $1.2 \mathrm{~mm}$ sample has lower tensile properties than the reference material (orange line). The modified $0.88 \mathrm{~mm}$ lab trial shows an improvement in strength levels, owing to its closer ferrite grain size and phase fractions to the commercial product.

The larger grain size and lower carbon content of the lab-produced samples tend to lower the UTS, YS and hardness compared to the industrial material. The Hall-Petch relationship in dual-phase steels has been studied in many research work [14-16]. The variations in $\sigma_{\mathrm{o}}$ (resistance of lattice to dislocation motion) and $k$ (strengthening coefficient) are large due to the complex nature of dual-phase steels. Many factors such as carbon concentration, volume fraction of martensite and the martensite distribution will all change the $\sigma_{\mathrm{o}}$ and $k$ value. Based on the literature [14-16], the following equation has been selected for this study, where $d$ is the ferrite grain size (refer to Table 7). Although some variation in these parameters is seen in the literature and thus obtaining accurate absolute values is difficult, the relative change in strength due to grain size is much more consistent:

$$
\begin{aligned}
& \sigma y=400+(1100 \hat{d(}-1 / 2)) \\
& \text { UTS }=700+(1000 \hat{d(-1 / 2))} .
\end{aligned}
$$

As a result, by comparing the commercial 1.2 and $0.88 \mathrm{~mm}$ lab benchmark samples, a $0.4-\mu \mathrm{m}$ smaller ferrite grain size in the $0.88-\mathrm{mm}$ sample should increase the UTS and YS by approximately 28 and $31 \mathrm{MPa}$, respectively. This is consistent with the $33 \mathrm{MPa}$ difference seen for both UTS and YS experimentally in Table 9 for the two lab samples. This suggests that the vast majority of the strength difference is due to the reduction in band spacing (and therefore grain size). When comparing with the commercial product, however, the 0.5 $\mu \mathrm{m}$ difference in grain size does not account for the large discrepancy between the YS measurements. The lab benchmark trial ends at the annealing simulation. However, a temper rolling process is usually introduced to the DP grades after the industrial annealing process to improve the continuous yielding behaviour and shape/flatness. If an annealed DP800 sheet passes through the temper rollers, usually $1 \%$ strain is applied. This pre-strain of the commercial product should increase the $Y S$ in a tensile test but not the UTS. By considering $1 \%$ of strain applied to the lab-produced $1.2 \mathrm{~mm}$ sample in the tensile data, then the new effective YS will increase to $525 \mathrm{MPa}$, and the $0.88-\mathrm{mm}$ sample will raise the YS further to $571 \mathrm{MPa}$. This brings the yield strength much more in-line with commercial variability considering $1 \%$ is a typical applied pre-strain (Figure 16(a)), with the elongation showing improved agreement also (Figure 16(b)).

\section{Conclusions}

RAP enables testing within research laboratories and virtual environments
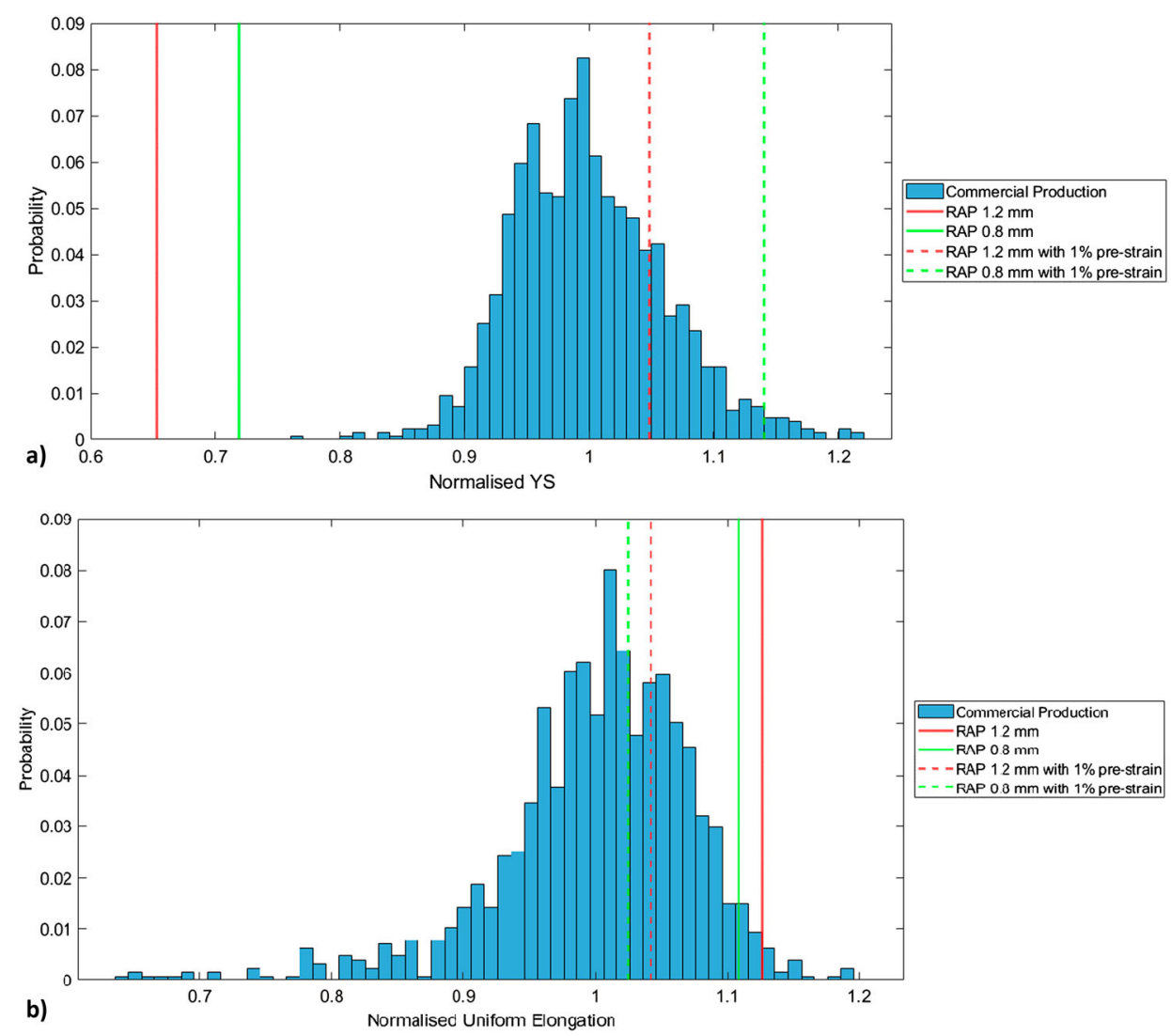

Figure 16. Normalised (a) yield strength and (b) uniform elongation of the lab DP800 benchmark alloy samples, before and after $1 \%$ pre-strain is considered. Compared with the commercial products range. 
rather than in the steel plant. The benchmark lab trial assessed here proved that the replication of the industrial DP800 product within the lab can be done within approximately two weeks testing time, from experimental design to comprehensive characterisation, allowing significant turn-around time for product development (72 tensiles or 20 hole expansion tests). More importantly, the scientific challenges that need to be considered to successfully produce the lab benchmark DP steel have been determined and overcome, giving confidence in the upscalability of laboratory findings for massproduced steel products.

After initial characterisation of the commercial product, thermal modelling for different ingot designs and prediction of SDAS was used in order to determine the cooling rate required on casting to achieve the same final band spacing after rolling from the RAP process as in full-scale production. The final band spacing achieved agreed well with the model prediction but due to limitations in the rolling process, a minimum thickness of $0.88 \mathrm{~mm}$ was achieved (rather than the desired $0.8 \mathrm{~mm}$ ) and as such the resultant band spacing was slightly coarser than in the commercial product.

Mechanical testing of the strip samples shows very good agreement in UTS, with the small discrepancy between the commercial and RAP lab $0.88 \mathrm{~mm}$ strip being attributed to the small difference in band spacing (and therefore grain size), as shown by Hall-Petch predictions. The as-annealed yield strength for the RAPproduced materials was significantly lower than that of the commercial product. This was attributed to the prestrain given commercially via a final temper rolling process, which had no influence on the UTS and elongation. The consideration of the temper rolling process post auto-tempering further demonstrates the accuracy and benefits of the RAP process developed at WMG as well as the importance of ensuring for the most influencing processes, full through-process replication when comparing lab and commercial products.

The successful replication of an alloy such as DP800 which replies both compositional and thermo-mechanical aspect for performance, gives confidence going forward that alteration/improvements made during this RAP process will show consistent properties when upscaled to full production, thus speeding up alloy development for commercial level production.

\section{Acknowledgements}

The authors would like to thank EPSRC for funding (grant number EP/S005218/1), WMG for their support and facilities and Tata Steel Europe for access to process ad production data.

\section{Disclosure statement}

No potential conflict of interest was reported by the author(s).

\section{Funding}

This work was supported by Engineering and Physical Sciences Research Council: [grant number EP/S005218/1].

\section{ORCID}

C. Slater (1) http://orcid.org/0000-0002-74914919

\section{References}

[1] Fonstein N. Dual-phase steels. Automotive Steels. 2017: 169-216.

[2] Mazaheri Y, Kermanpur A, Najafizadeh A. A novel route for the development of ultrahigh strength dual phase steels. Mater Sci Eng A. 2014;619:1-11.

[3] Springer $H$, Raabe D. Rapid alloy prototyping: compositional and thermo-mechanical high throughput bulk combinatorial design of structural materials based on the example of $30 \mathrm{Mn}-1.2 \mathrm{C}$-xAl triplex steels. Acta Mater. 2012;60(12):49504959.
[4] Innovations, Q. Materials design. [cited 2020 07].

[5] Lavery NP, Mehraban S, Pleydell-Pearce C, et al. Ironmaking \& steelmaking processes, products and applications combinatorial development and high throughput materials characterisation of steels combinatorial development and high throughput materials characterisation of steels.

[6] Lu Q, Xu W, Van Der Zwaag S. The design of a compositionally robust martensitic creep-resistant steel with an optimized combination of precipitation hardening and solid-solution strengthening for high-temperature use. Acta Mater. 2014;77:310-323.

[7] Liu C, et al. Composition design of a new type low-alloy high-strength steel. Mater Des. 1997;18(2):53-59.

[8] Li L. Microstructure and property control of advanced high strength automotive steels. In: Weng Y., Dong H., Gan Y, editor. Advanced Steels. Berlin Heidelberg: Springer; 2011. p. 265-274.

[9] Keeler S, Kimchi M, Mooney PJ. Advanced high-strength steels application guidelines. World Auto Steel, 2017. 6.0.

[10] Granbom Y. Structure and mechanical properties of dual phase steels - An experimental and theoretical analysis, in Royal Institute of Technology, KTH Industrial Engineering and Management. 2010, Stockholm.

[11] Volkova O, Heller HP, Janke D. Microstructure and cleanliness of rapidly Solidified steels. ISIJ Int. 2003;43:17241732.

[12] International, A., Standard test methods for tension testing of metallic materials, in ASTM E8/E8M-16ae1. 2016.

[13] Singh G, Singh R, Singh R. To study the effect of holding time and holding temperature on hardness and micro structure of alloy steel AISI4340. Int J Technol Comput. 2015;1(1):10-21.

[14] Peng-Heng C, Preban AG. The effect of ferrite grain size and martensite volume fraction on the tensile properties of dual phase steel. Acta Metall. 1985;33:897-903.

[15] Jiang Z, Guan Z, Lian J. Effects of microstructural variables on the deformation behaviour of dual-phase steel. Mater Sci Eng A. 1995;190(1-2):55-64.

[16] Etesami SA, Enayati MH. Microstructural evolution and recrystallization kinetics of a cold-rolled, ferrite-martensite structure during intercritical annealing. Metall Mater Trans A. 2016;47: 3271-3276. 